Book Power in Communication, Sociology and Technology

Ed. Angela Repanovici, Manolis Koukourakis, Tereza Khecyoyan

Series: Philosophy, Communication, Media Sciences

Available online at http://trivent-publishing.eu/

\title{
Biomechanics in Publication: Present State and Perspectives
}

\author{
Ileana-Constanta Rosca ${ }^{1}$ \\ ${ }^{1}$ Product Design, Mechatronics and Environment Department, \\ Transilvania University of Brasov, Romania
}

\begin{abstract}
The progress in biomechanics research is a basic package in the context of the dynamic development of the medicine and health dedicated sciences. As a relatively-new discipline, biomechanics started to be published in books not very long ago. Obviously, in parallel, a large volume of articles were published in different journals that are not grouped in books or monographs. The problem is: which is the best way to spread the research results in the specific domain - in journals or in books? How long is the delay to group the researches in a structured publication? In the moment of book apparition they are still new?
\end{abstract}

Keywords: Biomechanics; research; book, journal; proceedings.

DOI: 10.22618/TP.PCMS.20181.156013

This is an Open Access article distributed in accordance with the Creative Commons Attribution Non Commercial (CC-BY-NC-ND 4.0) license, which permits others to copy or share the article, provided original work is properly cited and that this is not done for commercial purposes. Users may not remix, transform, or build upon the material and may not distribute the modified material (http:/ / creativecommons.org/ licenses/by-nc/4.0/) 


\title{
Biomechanics in Publication: Present State and Perspectives
}

\author{
Ileana-Constanta Rosca \\ Product Design, Mechatronics and Environment Department, \\ Transylvania University of Brasov, Romania
}

\section{Introduction}

Biomechanics, as "the study of the movement of living things using the science of mechanics," was recognized as a clear discipline only a short time ago ${ }^{1}$, as its beginnings can be found in the early development of natural sciences. Human scientific interest on itself concerning physiology and implicitly biomechanics was only part of a wide range of challenges faced when trying to understand the world. In time, knowledge was organized and structured in separate disciplines, leading to fragmentation that increased until the last century. But as scientific knowledge increased, the gaps between disciplines continued narrow, and now we study interdisciplinary domains as biophysics, biochemistry and, among them, biomechanics. $^{23}$

Biomechanics provides the most important information necessary to improve the human movement from two points of view: performance improvement and the reduction of the consequences of injuries in synergy with other kinesiology domains. ${ }^{4}$ Human movement is generally accepted as being the relative movement of two segments of the human body and, viewing the high dynamic of the research in this field, the quantity of information increases rapidly. This situation led to the present state - a large number of papers in many publications mostly impossible to read not only because of their number but also because they are not systematized.

\section{Basic knowledge in biomechanics}

A good biomedical engineer is firstly a good engineer able to invent and design and, secondly is able to create new systems that have never existed before. Thus they take engineering courses to be able to create and design and, after a good knowledge accumulation, the inventive thinking can be cultivated. All curricula in medical engineering comprises a typically common subject - biomechanics. But it follows other ones that are also comprised in them. The most important is mechanics in the large sense of the term, i.e. solid rigid mechanics elasticity and plasticity, as well as the mechanics of continuum body

\footnotetext{
${ }^{1}$ H. Hatze, "The meaning of the term "biomechanics" Journal of Biomechanics 7(2) (1974): 189-190.

2 R.B. Martin, The Early History of Biomechanics. Presidential Lecture at the 23 $3^{\text {rd }}$ Annual Conference of ASB in Pittsburgh, PA (1999).

3 R.E.D. Ferdinands, "Advanced Applications of Motion Analysis in Sports Biomechanics" in the Proceedings of the 28th Conference of the International Society of Biomechanics in Sports, Northern Michigan University Marquette (2010).

${ }^{4}$ D. Knudson, Fundamentals of Biomechanics (New York: Springer Science+Business Media, 2007).
} 
and fields. All these serve as base for the biomechanical studies being intimately closed to needed mathematical and measurement instruments.

This is the reason that in all great biomechanics courses or books the first part is dedicated to the presentation of basic mechanics. Most of them begin with several chapters on kinematic, kinetic and static classical mechanics, 5678 presented abstractly or applied on the human movement analyze. But all this knowledge is accessible in any scholar specialized course and, it brings few new information on the specific domain of biomechanics. What is a very good contribution is the fact that some courses present many solved or proposed applications which facilitate the understanding of a quite abstract theoretical domain. There are few books 91011 that prolong the mechanical study in elasticity, plasticity and continuum mechanics, even most of the human body's components are composite, non-isotropic and non-homogenous and modern studies lye on the consideration of such properties of living tissues.

These are some few considerations on the general biomechanics books and courses. From another point of view, biomechanics can address different chapters of locomotor or different systems of the human body. We can briefly cite works only on gait, ${ }^{12} 13$ on spinal biomechanics ${ }^{14}$ or on computational techniques ${ }^{15}$ but, also on living tissues ${ }^{10}$ or some very known on human circulation and blood. ${ }^{11}$

Concerning the biomechanics study area, if we take into account the simple sense of human locomotion, works on other subsystems of the human body that locomotor are difficult to accept as being in the domain or they could be considered as frontier ones. But lying on the broader mean of locomotion accepting that any relative movement of a human part or organ in report to another can be considered as biomechanical movement, a lot of other works are part of biomechanics, even they address the limbs and the whole body or other organs as heart, lungs, liver, kidneys or any other living tissue. Also, we have the possibility to access the contributions of different authors in structured volumes edited by prestigious scientists and which cover a large range of sub-domains of biomechanics from the mechanics of hard and soft tissues, mechanics of microcirculation and of sanguine particles till the mechanics of senses and factors affecting the mechanical work in humans. ${ }^{12} 156$

Our days we can observe that the development of such works - of general interest or courses for students - began especially in the second half of the last century and touched almost the whole area of biomechanical study and are spread on all world continents, from Europe till Africa and Australia. They form a large basic knowledge on biomechanics but

\footnotetext{
${ }^{5}$ B.S. ,Hall Basic biomechanics, Fifth edition (New York: McGraw-Hill, 2007).

${ }^{6}$ R.D. Peterson; D.J. Bronzino, Biomechanics. Principles and Applications (Boca Raton: CRS Press, 2008).

${ }^{7}$ I. C. Rosca, I. Serban, Fundamente de biomecanica [Fundaments of biomechanics] (Brasov: Transylvania Univ. of Brasov, 2015).

8 A. Tözeren. Human Body Dynamics: Classical Mechanics and Human Movement (New York: SpringerVerlag, 2000).

9 Y.C. Fung, Biomechanics. Motion, Flow, Stress, and Growth (New York: Springer Science+Business Media, 1990).

10 Y.C. Fung, Biomechanics. Mechanical Properties of Living Tissues, $2^{\text {nd }}$ Edition (New York: Springer Science+Business Media, 1993).

${ }^{11}$ Y.C. Fung, Biomechanics. Circulation, $2^{\text {nd }}$ Edition (New York: Springer Science+Business Media, 1997).

${ }^{12}$ C.T. Leondes, Musculoskeletal Models and Techniques (Boca Raton, Florida: CRC Press, 2000).

${ }^{13}$ C.L. Vaughan, B.L. Davis, J.C. O'Connor, Dynamics of human gait (Cape Town: Kiboho Publishers, 1999).

${ }^{14}$ W.R. Haid Jr., R.B. Subach, E.G. Rodts Jr. Advances in spinal stabilization (Basel: Reinhardt Druck, 2003).

15 T.C. Leondes, Computer Tecbniques and Computational Methods in Biomechanics (Boca Raton, Florida: CRC

Press, 2001).
} 
are not up to date of the scientific research, even very necessary in large public information and in specialist formation.

\section{Dynamic biomechanical information publishing}

After the world was concerned on the industrial development to improve the human life comfort and on military advancement, we can see that at least in parallel with these two great goals the scientific world leans more and more on the human being assistance and healing. Assisting and security devices for normal people working in dangerous environment or for handicapped subjects evolve extremely rapidly and embrace the last progress in mini and nano technologies, materials informatics and robotics. This is possible on one side because of the general technical development and, on the other side, because of the important founds allocation for research specific establishments.

In this social context, it is natural that many journals arise and very early become well known due to the high scientific level of published papers and highly quoted by the great number of associated citations.

In present the highest quoted journals in biomechanics are: Biomechanics and Modeling in Mechanobiology, Journal of Biomechanics, Scandinavian Journal of Medicine \& Science in Sports, Computer Methods in Biomechanics and Biomedical Engineering, Journal of Biomedical Engineering-Transactions of the ASME, Clinical Biomechanics, Sports Biomechanics, Journal of Applied Biomechanics, Molecular \& Cellular Biomechanics, Acta of Bioengineering and Biomechanics and, Applied Bionics and Biomechanics. Their Impact factors for 2016 are between 3.036 (the first one) and 0.703 (the last one) and this seems to be rather low in report with other journals in medicine, materials and chemistry that are closely related to biomechanics. These biomechanics journals publish a high number of volumes and issues containing many important results of last minute specific research.

In parallel with periodical journals, proceeding of strong international meetings and congress are published in volumes constituting collection of weighty scientific achievements. ${ }^{16} 17$ 18 In the same range of interest, we must mention the interdisciplinary character of biomedical research in which biomechanics is almost all the time the first part and, thus, a lot of results are part of publications in many other journals of connected areas. On the other hand, biomechanics being fundamentally the application of mechanics on the human body's behavior many other journals of applied mechanics, mathematics and engineering publish results of biomechanical research. ${ }^{19} 20$

Most of journals publishing biomechanical research results are from the beginning open access or are very soon on internet sites which makes them accessible to the large interested public. But there is a problem concerning the level of conceptualization of the informed consent of authors, especially in Eastern European countries ${ }^{21}$ (Dima, 2014).

16 I. Serban, "Gait and Balance Analysis in People with Meniscal Tear" in COMEC 2015 proceedings (2015).

${ }^{17}$ C. Druga, A. Lupu, "Simple Circuit for Monitoring Brain Activity" in COMEC 2015 proceedings (2015).

18 O.A. Florea, I.C. Rosca, "A novel approach of the Stokes second problem for the synovial fluid in knee osteoarthrosis" Osteoartbritis and Cartilage 22 (2014): 109-110.

19 O.A. Florea, I.C. Rosca, "The Mechanical Behavior and the Mathematical Modeling of an Intervertebral Disc" Acta Technica Napocensis, 58(2) (2015): 213-218.

${ }^{20}$ R. Miclaus, A. Repanovici, N. Roman, "Biomaterials: Polylactic Acid and 3DPrinting Processes for Orthosis and Prosthesis" Materiale plastice [Plastic materials] 51(1) (2017): 98-102.

${ }^{21}$ L. Dima, A. Repanovici, D. Purcaru, et al., "Informed consent and E-communication in medicine" Revista romana de biotică [Romanian review of bioethics] 12(2) (2014): 37-46. 


\section{Conclusion}

Publications in biomechanics are present in most scientific publications: books, student courses, journals, proceedings collections, internet and, open sources, depositories. The dynamic of the research in this domain is remarkable, the research achievements are huge and this makes the documentation of specialists in this domain very difficult. Very few times does a structured book or course present up to date researches and thus courses are always late in reporting with other types of publications.

It should also be mentioned that most authors are not well informed on the conditions, facilities and their responsibility of publishing on-line.

The most of important biomechanics journals are in English and they do not accept any other language from authors who are not English native speakers. This makes the acceptance of their papers in interesting specific journals more difficult. Thus they have to use onerous proofing services which, together with the high publication fees limit the authors' contribution with interesting research results if they are not a part of a strong English language establishment. 